\title{
Universiteit
}

Leiden

The Netherlands

\section{Directed forgetting between, but not within, dissociative personality states.}

Elzinga, B.M.; Phaf, R.H.; Ardon, M.A.; Dyck, R. van

\section{Citation}

Elzinga, B. M., Phaf, R. H., Ardon, M. A., \& Dyck, R. van. (2003). Directed forgetting between, but not within, dissociative personality states. Journal Of Abnormal Psychology, 112, 237-243. Retrieved from https://hdl.handle.net/1887/14211

Version: $\quad$ Not Applicable (or Unknown)

License: $\quad$ Leiden University Non-exclusive license

Downloaded from: https://hdl.handle.net/1887/14211

Note: To cite this publication please use the final published version (if applicable). 


\title{
Directed Forgetting Between, But Not Within, Dissociative Personality States
}

\author{
Bernet M. Elzinga \\ Angelique M. Ardon
Parnassia, The Hague
}

University of Leiden and Vrije Universiteit Amsterdam

\author{
R. Hans Phaf \\ University of Amsterdam
}

Richard van Dyck

Vrije Universiteit Amsterdam

\begin{abstract}
To investigate amnesia between identities in dissociative identity disorder (DID), the authors assessed explicit and implicit memory performance on a directed-forgetting task in 12 DID patients who switched from one state to an "amnesic" state between presentation and memory testing. DID patients were instructed either to remember or to forget neutral and emotional words. Besides an overall decrease in explicit memory, patients demonstrated selective forgetting of to-be-forgotten, but not of to-beremembered words in the amnesic state. Patients did not exhibit any directed forgetting within the same state. Implicit memory was fully preserved across states. Independent of state, patients recalled more emotional than neutral information. These results may extend the conceptualization of memory processes in DID, suggesting an important role for retrieval inhibition.
\end{abstract}

Dissociative identity disorder (DID) is an intriguing and complex disorder. In the Diagnostic and Statistical Manual of Mental Disorders (DSM-IV; American Psychiatric Association, 1994) DID is described as "a failure to integrate various aspects of identity, memory, and consciousness" with the essential feature that functions are disintegrated so severely that there are "two or more distinct identities or personality states that recurrently take control of behavior" (p. 484). The nature and etiology of identities or "alters" is still a matter of debate, however, that is mainly centered around two competing views (see Elzinga, van Dyck, \& Spinhoven, 1998; Lilienfeld et al., 1999). Whereas the posttraumatic model maintains that alters can best be conceptualized as a defensive response to childhood trauma (see Gleaves, 1996; Putnam, Guroff, Silberman, Barban, \& Post, 1986), the sociocognitive model conceptualizes alters in terms of cultural scripts that are shaped by psychotherapists, media portrayals and sociocultural expectations (see Spanos, 1994). Currently, there is a lack of consensus on this issue among researchers in the field. As a consequence, we will adopt a pragmatic stance and use the

Bernet M. Elzinga, Section of Clinical and Health Psychology, University of Leiden, Leiden, The Netherlands, and Department of Psychiatry, Vrije Universiteit Amsterdam, Amsterdam, The Netherlands; R. Hans Phaf, Psychonomics Department, University of Amsterdam, Amsterdam, The Netherlands; Angelique M. Ardon, Parnassia, Clinic for Intensive Treatment, The Hague; Richard van Dyck, Department of Psychiatry, Vrije Universiteit Amsterdam, Amsterdam, The Netherlands.

This study was supported by Grant 575-29-003 from the Foundation for Behavioral and Educational Sciences of the Netherlands Organization of Scientific Research awarded to Richard van Dyck and R. Hans Phaf. We thank J. F. Kihlstrom for helpful comments on this article.

Correspondence concerning this article should be addressed to Bernet M. Elzinga, Section of Clinical and Health Psychology, University of Leiden, 2300 RB Leiden, The Netherlands. E-mail: elzinga@fsw.leidenuniv.nl
$D S M-I V$ as a point of departure without making any a priori claims about the nature of so-called "identities."

A characteristic feature of DID is the occurrence of apparently severe amnesic symptoms (see Dorahy, 2001, for an excellent review). In fact, according to the criteria of the $D S M-I V$, the "inability to recall important personal information that is too extensive to be explained by ordinary forgetfulness" (p. 484) is even one of the hallmarks of DID. DID patients often complain about "losing time"; for example, they may suddenly find themselves in places or unexpected situations without any memory of how they arrived there. Besides a repetitive loss of memory for current episodes, an overall loss of autobiographical memory for some extended time in childhood is frequently reported (Kihlstrom, 2001; Kihlstrom, Tataryn, \& Hoyt, 1993). Reminiscent of the distinction between explicit and implicit memory in the organic amnesic syndromes, it has been assumed that psychogenic amnesia in DID patients affects conscious recollection, but not nonconscious memory processes, so that patients may be emotionally affected by an emotional event without having a conscious recollection of it (Kihlstrom, 2001; Kihlstrom et al., 1993).

Since the beginning of the 20th century researchers have tried to understand the etiology of psychogenic amnesia. In a variety of theories, amnesia has been regarded as the result of intentional processes to discard negative emotions (Terr, 1991), as a physiologically induced phenomenon caused by chronic stress (Bremner, 1999), as a state-dependent memory (Eich, Macauley, Loewenstein, \& Dihle, 1997), and as the (conscious or nonconscious) enactment of sociocultural expectations regarding memory processes in DID (Spanos, 1994). It is remarkable that in contrast to the prominent role of amnesia in the diagnosis of DID and numerous clinical observations, experimental studies on amnesia in DID are rare.

In a study applying a directed-forgetting task, we tested whether amnesia might be the result of a cognitive avoidance style that 
enables traumatized persons to selectively forget or discard threatening information on a conscious level (Elzinga, de Beurs, Sergeant, van Dyck, \& Phaf, 2000). In this task different categories of words are first presented with the instruction either to remember or to forget each word, which is followed by a memory test of the words. Several studies in nonclinical populations have shown that with this procedure information can be forgotten at will (see Johnson, 1994, for a general review). Current models propose that multiple mechanisms underlie the effects of intentional forgetting, including differential encoding of to-be-remembered and to-beforgotten items resulting from selective rehearsal of remember words, and a repression-like process at the time of retrieval that prevents forget words from being recovered (Anderson \& Neely, 1996; Johnson, 1994).

The directed-forgetting task has been used as a method to assess whether traumatized patients engage in selective forgetting of trauma-related information (see Cloitre, Cancienne, Brodsky, Dulit, \& Perry, 1996; Korfine \& Hooley, 2000; McNally, Clancy, \& Schacter, 2001; McNally, Metzger, Lasko, Clancy, \& Pitman, 1998). If traumatized individuals are more skilled in avoiding the encoding and/or retrieval of threatening information, one would expect a more pronounced forgetting of negative or threatening words. However, contrary to expectations, in our study DID patients did not deliberately forget sex-related words on a conscious level (Elzinga et al., 2000). Relative to the two control groups high and low in dissociation, and to all other word categories, DID patients even exhibited the highest recall of to-be-forgotten sex words, thereby reversing the otherwise robust directed forgetting effect.

These findings suggest that the apparent amnesia in DID patients is not primarily the result of a conscious, intentional strategy of avoidance, at least not within the same state. A theory reflected in the DSM-IV and common in clinical practice, states that memories in DID patients are compartmentalized in different personality states, suggesting that these patients may only be capable of selectively forgetting emotionally charged memories or words when they "switch" from one identity to another (see Ludwig, Brandsma, Wilbur, Bendfeldt, \& Jameson, 1972; Silberman, Putnam, Weingartner, Braun, \& Post, 1985). The purpose of this study was to investigate whether DID patients can selectively forget emotional information when they are asked to switch from one state to a second "amnesic" state between presentation of the words and the testing phase.

Systematic research on between-identities amnesia in dissociative disorders has been limited to a number of case reports (Allen \& Movius, 2000; Dick-Barnes, 1987; Ludwig et al., 1972; Nissen, Ross, Willingham, MacKenzie, \& Schacter, 1988; Peters, Uyterlinde, Consemulder, \& van der Hart, 1998; Silberman, et al., 1985), and one experimental study (Eich et al., 1997). In these studies, dissociative patients generally tend to report no (or limited) between-identities recall on direct, explicit tasks, whereas they do show memory transfer on more indirect tests of memory. In the earlier studies, these findings have been interpreted as consistent with the idea that explicit memory is reduced in DID, whereas implicit memory is not (see Dorahy, 2001). Transfer of information that is inconsistent with this model was often explained by the fact that only neutral, nonthreatening information was used, suggesting that amnesia would have been complete if emotional material had been presented (Ludwig et al., 1972; Sil- berman et al., 1985). So far, to our knowledge, it has not yet been tested how memory for emotional material is affected by switching states. In recent years, an alternative interpretation has been proposed suggesting that the differential effects on memory tasks may instead be related to the sensitivity of the tasks to the participants' ability to control or inhibit responses, assuming that DID patients may withhold their responses in more transparent, often explicit, memory tasks, but may not be able to do so in more indirect measures of memory (see Allen \& Iacono, 2001; Bowers \& Schacter, 1990).

The purpose of this study was to investigate the extent and the nature of explicit versus implicit memory for neutral and emotional material between states in DID patients, adopting the directed-forgetting method. Twelve DID patients, who were able to alternate, upon experimenter's request, between two states ${ }^{1}$ participated. Patients claimed to have no conscious awareness between these states. The study consisted of three phases. During the first phase, patients were presented intermixed neutral and emotional words with the instruction either to remember or to forget each word (the directed-forgetting task), and a picturefragment completion task. In Phase 2, patients were asked to switch to the second state, in which explicit and implicit memory was assessed of information presented in State 1. In Phase 3, patients were asked to switch back to the first state, and were administered parallel versions of the implicit and explicit tasks to assess memory within the same state. To reduce the possibility of intentionally withholding responses, implicit tasks were selected that are associated with limited test awareness.

If cognitive avoidance only works between, but not within, dissociative states, instructions to forget (emotional material) would be particularly effective when explicit memory is tested in the amnesic state. Because amnesia is only assumed to affect conscious memory performance, no differences in nonconscious memory performance were expected.

\section{Method}

\section{Participants}

Twelve DID patients (11 women, 1 man) participated, averaging 40.17 $( \pm 9.15)$ years in age. Patients were recruited by clinicians at two clinics (Parnassia, Clinic for Intensive Treatment, The Hague, and MultiFunctional Unit, MFE, Emmen, The Netherlands) and at the time of testing each patient was engaged in a psychotherapeutic program. Patients were asked to participate in the study by their clinician if they (a) fulfilled criteria for DID, (b) reported interidentity amnesia, (c) would be capable of assuming and maintaining one of two amnesic identities upon request of the experimenter, and (d) were functioning at a sufficiently high level that the participation in the study would not impede therapeutic progress. Patients were given oral and written information about the aim of the study. It was further explained that, over the course of a 90-min session, the experimenter would request that they alternate between two personality states or identities and that each identity would be asked to perform a series of cognitive tasks involving neutral and emotional material, provided that at least one of the two identities has no conscious awareness of, or direct access to, the other's experiences. Within these restrictions, choice of

\footnotetext{
${ }^{1}$ The term states is being used in a purely operational way, to reflect the fact that a patient has attempted to enter a different identity or personality state.
} 
identities was left to the patients. Patients were informed that participation was entirely voluntary. Recruitment and testing of participants were in accordance with the American Psychological Association's ethical guidelines regarding the use of human participants. Testing was carried out by the first author.

Diagnosis was made according to the criteria for DID using the Dutch translation of the Structured Clinical Interview for DSM-IV Dissociative Disorders (SCID-D; Boon \& Draijer, 1994; Steinberg, Cicchetti, Buchanan, Hall, \& Rounsaville, 1993). The Dutch version of the SCID-D has a good test-retest reliability $(\kappa=.96)$ and a good concurrent and discriminant validity (100\% and $98 \%$ respectively; see Boon \& Draijer, 1994). The Dissociation Questionnaire (Dis-Q; Vanderlinden, van Dyck, Vandereycken, Vertommen, \& Verkes, 1993), a 63-item self-report measure, was administered to quantify dissociative trait symptoms. The Dis-Q has a good internal consistency (Cronbach's $\alpha=.96$ for the total scale). The test-retest reliability is .94 for the total score over 3 to 4 weeks. Patients scored 3.44 ( \pm 0.57) on the DIS-Q, which lies in the average range for DID patients (see Vanderlinden et al., 1993).

Nine of 12 patients had a comorbid clinical diagnosis of posttraumatic stress disorder (PTSD), 2 patients had a borderline personality disorder, and 2 had traits of borderline personality disorder. All participants gave written informed consent for their participation in a protocol approved by the human investigation committee of the University of Amsterdam.

\section{Materials}

Directed forgetting study. Ninety-six Dutch words served as stimulus words in the directed-forgetting task: 48 had a threatening or sexual connotation (e.g., perpetrator, sperm, trauma) and 48 were neutral (e.g., balcony, bread, newspaper). All words had unique word stems of two or three letters. The normative probability of producing the selected words as a first response to their corresponding stems averaged 5\% (e.g., within a nontraumatized sample 1 of 20 participants would complete the word stem to the target word if it had not been studied before (Phaf \& Wolters, 1991). The 96 words were divided randomly into two lists that were rotated over the remember/forget instructions. For testing purposes four equivalent lists were compiled, each composed of 24 words ( 6 to-be-forgotten neutral, 6 to-be-forgotten emotional, 6 to-be-remembered neutral, and 6 to-beremembered emotional words). These lists were randomly divided over four testing conditions (cued recall in State 1, cued recall in State 2, perceptual identification in State 1 , and perceptual identification in State 2).

Picture-fragment completion task. For the picture-fragment completion task eight sets of pictures were selected, depicting common objects or animals (e.g., horse, chair). From these pictures eight sets of successive picture fragmentation were prepared. To assess repetition priming, the sets were divided randomly over testing in State 1 and State 2. To obscure the purpose of memory testing, in each phase four new picture sets were presented together with the target sets. All tasks, except for the cued-recall task, were performed on an iMac computer.

\section{Procedure}

Testing was completed in a 90-min session. The session started with an introduction about the study's aims and methods, after which informed consent was obtained. Patients were told that the purpose of the research was to better understand memory processes in different personality states. Patients had already discussed which states would take part in the study and how to switch between states with their therapist in individual sessions. This was again briefly discussed in the session. No hypnosis was used to facilitate a switch between identities. The memory study consisted of three phases, summarized in Table 1.

Phase 1. In Phase 1 the patient switched to State 1. First, the directedforgetting task was presented with the standard instructions (see MacLeod, 1989). Participants were told that a list of words would be presented and that after the presentation of each word, a cue would appear indicating whether they had to remember or forget the word. The cue was either "RRRR," instructing the patient to remember the word, or "FFFF," instructing the patient to forget the word. Participants were told that "forgetting some words would improve their ability to remember other words, when their memory for this long and difficult list would be tested later." Words were presented in the center of a computer screen for $3 \mathrm{~s}$, followed by a $0.5 \mathrm{~s}$ empty interval and a $2 \mathrm{~s}$ presentation of the cue. The screen was blank for $1.5 \mathrm{~s}$ and then the next word appeared.

Following the directed-forgetting task, the picture-fragment completion task was administered as a first presentation of the pictures. Eight sets of pictures were displayed on a computer screen for $1 \mathrm{~s}$, starting with the most fragmented version, and ending with the full depiction of the object. Patients were asked to identify, if possible, the object, by typing the correct answer in an answer box that appeared on the screen after each presentation. If participants had no idea what the image represented, they could leave it blank. After pressing the return key, the next version of the image appeared.

Phase 2. In Phase 2 the patient switched to the amnesic State 2. This was prompted by the following statement: "This was the first part of the study. State 1 can now move backward and you can let State 2 come forward." The patient was then asked if he or she had any recollection of what had happened in Phase 1. All patients denied any conscious recollection of Phase 1 and were, therefore, again informed about the procedure.

Implicit memory was assessed first with the perceptual identification task. In the perceptual identification task 48 words were flashed briefly on a computer screen followed by a mask of letters (ZXTVQRBPCDS) for $1 \mathrm{~s}$, after which participants were asked to type in the word they guessed had been presented. The screen remained blank for $1 \mathrm{~s}$, and then the next word appeared. Of the 48 words, 24 (12 emotional, 12 neutral) corresponded to one of the four word lists presented in the directed-forgetting task, and 24 were new (12 emotional, 12 neutral). Because the time needed for identifying words appeared to be rather variable among patients, an individual threshold was determined for each patient, so that new words were identified in approximately $50 \%$ of the cases $(M$ presentation duration $=68.8$ $\mathrm{ms} \pm 9.1 \mathrm{~ms})$

Table 1

Outline of the Study Procedure

\begin{tabular}{ccll}
\hline Phase & Personality state & \multicolumn{1}{c}{ Memory tasks } & Memory type \\
\hline 1 & 1 & $\begin{array}{l}\text { Word study with directed-forgetting instruction } \\
\text { Picture-fragment completion (first presentation) }\end{array}$ & Study phase \\
2 & 2 (amnesic) & $\begin{array}{l}\text { Perceptual identification } \\
\text { Picture-fragment completion (second presentation) }\end{array}$ & Implicit test \\
& & Implicit test \\
& 1 & Pued recall & Explicit test \\
3 & Picture-fragment completion (third presentation) & Implicit test \\
& & Implicit test \\
& & Cued recall & Explicit test \\
\hline
\end{tabular}




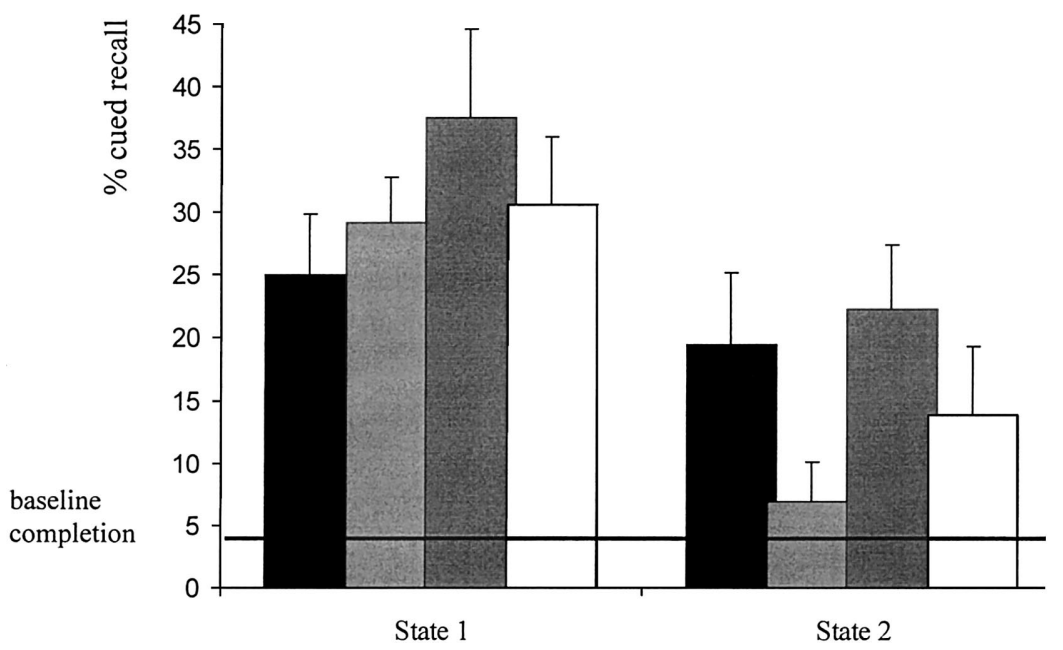

Figure 1. Mean cued-recall performance (with standard errors) for patients in States 1 and 2; baseline completion of the words is $5 \%$. Black bars $=$ neutral remember; light gray bars = neutral forget; dark gray bars $=$ emotional remember; white bars $=$ emotional forget.

The perceptual identification task was followed by a second presentation of the picture-fragment completion task to assess repetition priming. Among the picture sets that were previously presented in Phase 1, four new picture sets were added to obscure memory testing. Instructions were similar to those given in Phase 1.

After having explained that words had been presented in Phase 1, the cued-recall task was administered as a test of (predominantly) explicit memory. Participants were presented 24 word stems on paper, corresponding to one of the four lists, with the instruction to "complete the word stems, if possible, to previously seen words and otherwise to complete the stem to the first word that comes to mind." Participants were asked to complete all the stems to prevent "simulating" amnesia by simply leaving the stems blank.

Phase 3. In Phase 3 the patient switched back to State 1. Parallel versions of the perceptual identification, picture-fragment completion, and cued-recall task were administered. Following the final test, the patient was thoroughly debriefed. The purpose of the study was explained, patients were given the opportunity to report their experiences, and were encouraged to ask any questions related to the study. It was further ascertained that patients were emotionally stable before they left.

\section{Results}

\section{Cued Recall}

Average proportions of emotional and neutral target words produced in the cued-recall task as a function of state at recall are shown in Figure 1. First, we conducted a traditional omnibus $2 \times$ $2 \times 2$ (State 1 vs. State $2 \times$ Neutral vs. Emotional Words $\times$ Remember vs. Forget Instruction) repeated-measures analysis of variance (ANOVA) and computed effect sizes for all major outcomes. Second, we conducted focused $t$ tests to test specific predictions. All tests were two-tailed.

The omnibus ANOVA revealed that patients recalled more target words in the same state $(M \pm S E M=30.5 \pm 2.3 \%)$ than in the different state $(15.6 \pm 2.7 \%), F(1,11)=18.23, p<.001$, $d=1.73$. $^{2}$ In absolute terms, emotional words were recalled more often than neutral words (emotional words $=26.0 \pm 2.8 \%$ vs. neutral words $=20.1 \pm 1.9 \%$ ), although this difference failed to reach full significance, $F(1,11)=3.54, p=.086, d=0.77$. No difference was found for word valence between states, $F(1$, $11)=0.05, n s$. The omnibus ANOVA did not yield an overall interaction between instruction and state, $F(1,11)=1.28$, ns. According to our hypothesis, directed forgetting would occur in State 2, but not in State 1. Contrast analyses indicated that the results were in accord with these predictions: directed-forgetting effect was not found in State $1, t(11)=0.26, n s, d=0.16$, whereas in State 2, to-be-forgotten words (TBF) were tended to be recalled less often than to-be-remembered (TBR) words, $t(11)=1.99, p<$ $.072, d=0.81$. The prediction that recall of emotional words would be reduced compared to neutral words in State 2 was not confirmed, $t(11)=1.05, n s, d=0.44$. Consistent with the omnibus ANOVA, the mean recall was even in the opposite direction.

\section{Perceptual Identification Task}

Figure 2 shows the average percentages of emotional and neutral old words (i.e., presented in the directed-forgetting task) and new words that were correctly identified in the perceptual identification task as a function of state at test. The difference between the percentage correctly identified old versus new words represents the degree of priming. A $2 \times 2 \times 2$ (State 1 vs. State $2 \times$ Old vs. New Words $\times$ Neutral vs. Emotional Words) repeatedmeasures ANOVA was performed. Regardless of state, old words were identified more often than new words (old words $=65.2 \pm 4.7 \%$ vs. new words $=50.0 \pm 4.6 \%$, providing evidence for repetition priming, $F(1,11)=44.41, p<.0001$, $d=0.94$. The extent of priming was not qualified by any experimental manipulation. Patients showed as much priming in the same state $(13.4 \pm 6.9)$ as in the amnesic state $(16.8 \pm 4.1), F(1$, $11)=0.20, n s, d=0.22$. Directed-forgetting instructions had no influence on perceptual identification of words (TBR words $=62.9 \pm 5.8 \%$ vs. $\mathrm{TBF}$ words $=67.5 \pm 4.3 \%), F(1$,

\footnotetext{
${ }^{2}$ Cohen's $d$ effect size (differences scores divided by pooled SDs).
} 


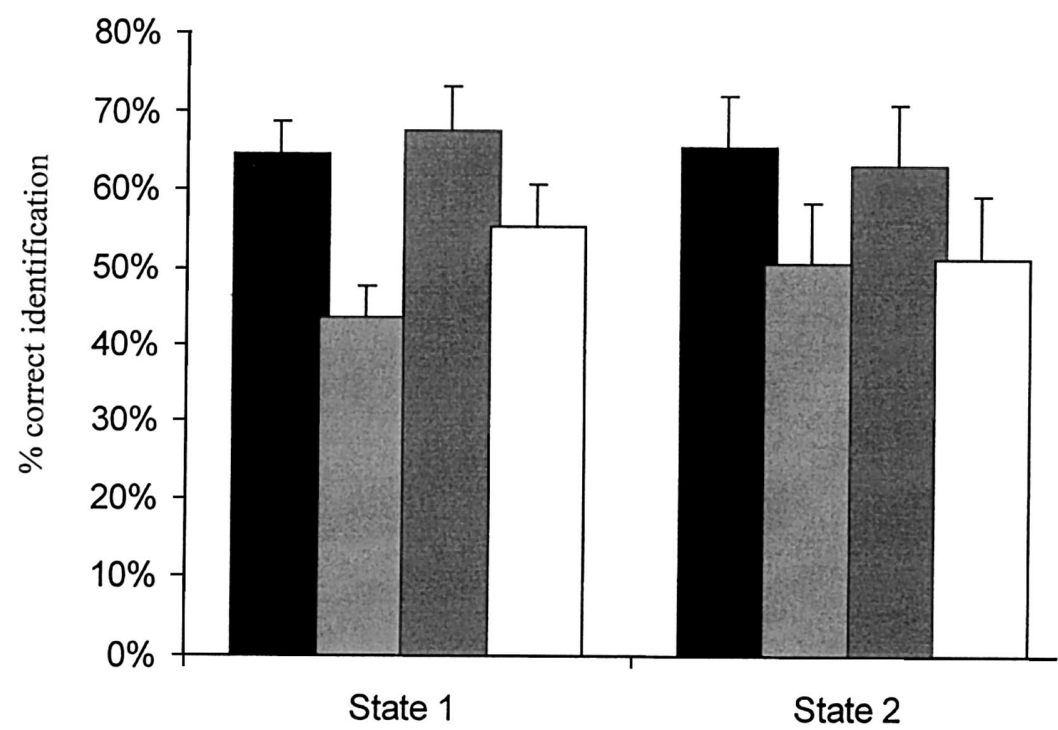

Figure 2. Mean percentage of correct perceptual identification (with standard errors) of old and new words by patients in States 1 and 2. Black bars = old neutral; light gray bars = new neutral; dark gray bars $=$ old emotional; white bars $=$ new emotional.

$11)=1.47, n s, d=0.27$. Neutral words $(55.9 \pm 3.8 \%)$ were identified as accurately as emotional words $(59.3 \pm 5.5 \%), F(1$, $11)=1.68, n s, d=0.21$. No other effects were found in this analysis.

\section{Picture-Fragment Completion}

The results reflect a sample of 11 participants, because 1 participant was not able to complete the test, owing to technical error. A one-factor (State 1 vs. State 2) repeated-measures ANOVA on the mean difference between the first and second identification of the pictures revealed that priming was as strong between states $(0.71 \pm 0.23)$ as within the same state $(1.18 \pm 0.17), F(1$, $10)=2.48, n s, d=0.71$. Priming was significant between states, $t(11)=3.14, p<.05$.

\section{Discussion}

Consistent with our first hypothesis, dissociative patients showed directed forgetting between states, but not within the same identity state. This was reflected by the large effect size $(d=0.81)$ associated with the enhanced recall of to-be-remembered words relative to to-be-forgotten words in the amnesic state, whereas only a marginal effect size $(d=0.16)$ was associated with this contrast within the same state. The ANOVA did not yield a significant interaction between state and directed forgetting, however. This may reflect the relative insensitivity of the omnibus ANOVA to detect important effects, particularly with relatively small sample sizes.

The absence of directed forgetting within the same state replicates previous findings in dissociative patients (Elzinga et al., 2000) and is in line with directed-forgetting patterns found in other traumatized patients, including patients with PTSD (McNally et al., 1998) and borderline personality disorder (Cloitre et al., 1996; Korfine \& Hooley, 2001). Given the high comorbidity of PTSD in our sample, the failure to selectively forget trauma-related material is probably not specific for dissociative psychopathology, but presumably characterizes symptomatic traumatized patients in general. This pattern deviates substantially from findings in nonclinical populations, where the directed-forgetting instruction consistently yields enhanced recall of to-be-remembered words compared to words that have to be forgotten, even when emotional words are presented (e.g., Elzinga et al., 2000; see also control subjects in Johnson, 1994; McNally et al., 1998). Keeping in mind that patients denied conscious recollection of the tasks that were administered in State 1, let alone the instructions that were presented together with the words, it was remarkable that DID patients exhibited directed forgetting when tested in the amnesic State 2, both for emotional and neutral words. Thus, whereas DID patients may not be able to inhibit or selectively forget information within the same state, they seem to do so when switching to a different state. This differential pattern of recall within distinct personality states may distinguish patients with DID from other traumatized subgroups, including patients with PTSD or borderline personality disorder.

The second purpose of this study was to determine whether amnesia in DID mainly disrupts explicit memory, leaving implicit memory unaffected (see Kihlstrom, 2001). In line with the expectations, DID patients showed a strong reduction of explicit memory performance between states $(d=1.73)$, whereas implicit memory was mainly preserved. Repetition priming, as a measure of implicit memory between states, was particularly evident in the perceptual identification task and, to a lesser extent, in the picturefragment completion task. These results extend previous findings of preservation of implicit memory and relative loss of explicit memory across states in patients with DID (see Dorahy, 2001).

Despite the clear reduction of explicit memory in State 2, this study provides no clear support for the self-reports of patients of having no conscious recollection of information that was presented 
to them in State 1. The percentages of word recall indicated that cued recall in State 2 was enhanced compared to the baseline completion rate of $5 \%$, particularly for neutral (19\%) and emotional $(22 \%)$ to-be-remembered words. This seems to reflect a preservation of explicit memory within the apparent amnesic state. Given the fact that the baseline completion rate was obtained in a nontraumatized, nonclinical sample, a direct comparison of the percentage of word recall with the baseline rate may not be totally reliable, however, because spontaneous filling in may be somewhat different in a traumatized sample, particularly in the case of emotional words. Furthermore, to prevent simulating amnesia by simply leaving the word stems blank, patients were instructed to fill in the first word that came to mind if they were not able to consciously retrieve a target word in the cued-recall task. To the extent that patients guessed, the cued-recall task may therefore have tapped implicit memory, too. Because the directed-forgetting effect generally arises under conditions of explicit memory (e.g., no effects of instruction were found in the perceptual identification task), explicit memory seems to have contributed substantially to memory performance in State 2, however.

In contrast to the hypothesis that amnesia has the function to ward off negative or threatening material, DID patients did not show a reduced recall of emotional words relative to neutral words in State 2. Irrespective of state, DID patients even tended to recall emotional words more often than neutral material. Although not fully significant in the omnibus ANOVA, this was a rather large effect in terms of effect sizes $(d=0.77)$. This finding seems to be inconsistent with the idea that switching from one personality to another has the function of avoiding emotionally charged memories. On the other hand, this pattern is similar to findings for patients with organic amnesia, in whom emotional arousal improved recognition and recollection of pictures (Hamann, Cahill, \& Squire, 1997).

The purpose of this study was to investigate the extent and the nature of memory for neutral and emotional material between states in DID patients. A direct comparison of the directedforgetting patterns between- versus within-personality states might help to clarify the memory processes that may be involved in the amnesic symptoms of DID patients. The different directedforgetting patterns in State 1 versus State 2 suggest that the reduced recall of forget words in State 2 cannot be exclusively due to differential encoding of the words (as this would have resulted in similar directed-forgetting patterns, regardless of the state of recall). Apparently, an inhibitory process at the time of retrieval played an important role in the reduced recall of to-be-forgotten words in State 2. This implies that, paradoxically, amnesia involved some retrieval of information related to the original instructions. These findings are in line with a recent electrophysiological study showing that, besides a differential encoding of to-beremembered versus to-be-forgotten words, retrieval inhibition of to-be-forgotten words played an important role in the directedforgetting effect (Ullsperger, Mecklinger, \& Müller, 2000). Generalized to memory processes outside the lab, these findings suggest that amnesia in DID patients is (partly) the result of inhibitory processes during retrieval of information or memories within one specific state, whereas this information may be freely remembered in a different state. The model of retrieval inhibition may also explain why some memory tests yield evidence for forgetting, whereas others reveal preserved, or even enhanced, memory pro- cessing (see Dorahy, 2001). In tests in which inhibition is relatively easy (e.g., free recall), information may be successfully inhibited. When more specific cues are presented, however, as in the picture-fragment completion task, inhibition may fail, which in any real-life situation may result in the recollection of unpleasant or even traumatic memories.

These results may offer an interesting extension of the conceptualization of memory processes in DID. The finding of (partial) explicit transfer of information between states does not support the idea that memory in DID patients is compartmentalized in several, strictly separate, memory systems, each related to a specific personality state. Some limitations of the study need to be taken into account, however, when generalizing these findings to the clinical realm. First, it is unclear to what extent memory for emotional word lists can be generalized to memory for personally meaningful, threatening negative events: In what sense does the word "perpetrator," for instance, really represent the patient's experience of abuse? Second, it cannot be ruled out that some patients may not have changed states (completely), even though all patients ascertained that they had done so and that they were amnesic for everything that had happened in the first part of the experiment. This problem cannot be tackled easily, however, because there are simply no objective tools available to verify that patients really switched between states. Third, the directed-forgetting instructions themselves may have induced a pattern of selective recall and/or forgetting by drawing attention to the remember words, resulting in memory processes that may not occur under normal circumstances. Moreover, it cannot be ruled out that other processes may be at work in the etiology of amnesia in DID patients that have not been addressed by the directed-forgetting paradigm (e.g., hypnotic induction). These factors do not warrant such a far-reaching conclusion that amnesia in DID would not exist. On the other hand, it is also important to keep in mind that the claim of dense amnesia between states, which would apply to any sort of experiences and certainly to any sort of words (including words that had to be remembered), was not substantiated by the experimental findings.

In conclusion, this study highlights the importance of informing the debate about memory functioning in DID gained through experimental data. The data here support the notion that memories in patients with DID may, to a certain extent, be state dependent, with a relative disruption of explicit memory between states. The partial preservation of explicit memory between states, on the other hand, does not support the strong version of the dissociation hypothesis, that alters are "truly" distinct identities with fundamentally separate memory systems and information-processing capacities. This study does not speak to the reality of DID or to the nature of alters, nor was it meant to. On the basis of these findings it cannot be decided whether the reduced explicit memory performance between states is related to a distinct organization of explicit memory within various states, or that it reflects the selective disruption of intentional as opposed to automatic uses of memory between states. Whereas the first interpretation may be considered in line with the posttraumatic model (Gleaves, 1996; Putnam et al., 1986), the latter might be more harmonious with a sociocognitive approach, assuming that patients with DID may withhold their responses as part of (nonconscious) role-playing (Spanos, 1994). At this point, more research is needed to address the specific question of whether a history of trauma or the enactment of a 
dissociative role is the most common factor in the etiology of personality states in DID and its related memory processes.

\section{References}

Allen, J. J. B., \& Iacono, W. G. (2001). Assessing the validity of amnesia in dissociative identity disorder: A dilemma for the DSM and the courts. Psychology, Public Policy, and Law, 7, 311-344.

Allen, J. J. B., \& Movius, H. L. (2000). The objective assessment of amnesia in dissociative identity disorder using event-related potentials. International Journal of Psychophysiology, 38, 21-41.

American Psychiatric Association. (1994). Diagnostic and statistical manual of mental disorders (4th ed.). Washington DC: Author.

Anderson, C. M., \& Neely, J. H. (1996). Interference and inhibition in memory retrieval. In E. Ligon Bjork \& R. A. Bjork (Eds), Memory (pp. 237-313). San Diego, CA: Academic Press.

Boon, S., \& Draijer, N. (1994). Gestructureerd Klinisch Interview voor de vaststelling van DSM-IV Dissociatieve Stoornissen (SCID-D) [Structured Clinical Interview for the Assessment of DSM-IV Dissociative Disorders]. Lisse, The Netherlands: Swets \& Zeitlinger.

Bowers, J. S., \& Schacter, D. L. (1990). Implicit memory and test awareness. Journal of Experimental Psychology: Learning, Memory, and Cognition, 16, 404-416.

Bremner, J. D. (1999). Does stress damage the brain? Biological Psychiatry, 45, 797-805.

Cloitre, M., Cancienne, J., Brodsky, B., Dulit, R., \& Perry, S. W. (1996). Memory performance among women with parental abuse histories: Enhanced directed forgetting or directed remembering? Journal of Abnormal Psychology, 105, 204-211.

Dick-Barnes, M. (1987). Behavioral measures of multiple personality: A single case study with a 15-year follow-up. Psychological Medicine, 5, $18-26$.

Dorahy, M. J. (2001). Dissociative identity disorder and memory dysfunction: The current state of experimental research and its future directions. Clinical Psychology Review, 21, 771-795.

Eich, E., Macauley, D., Loewenstein, R. J., \& Dihle, P. H. (1997). Memory, amnesia and dissociative identity disorder. Psychological Science, 8, 417-422.

Elzinga, B. M., de Beurs, E., Sergeant, J. A., van Dyck, R., \& Phaf, R. H. (2000). Dissociative style and directed forgetting. Cognitive Therapy and Research, 24, 279-295.

Elzinga, B. M., van Dyck, R., \& Spinhoven, P. (1998). Three controversies about dissociative identity disorder. Clinical Psychology and Psychotherapy, 5, 13-23.

Gleaves, D. H. (1996). The sociocognitive model of dissociative identity disorder: A reexamination of the evidence. Psychological Bulletin, 120, 42-59.

Hamann, S. B., Cahill, L., \& Squire, L. R. (1997). Emotional perception and memory in amnesia. Neuropsychology, 11, 104-113.

Johnson, H. M. (1994). Processes of successful intentional forgetting. Psychological Bulletin, 116, 274-292.

Kihlstrom, J. F. (2001). Dissociative disorders. In P. B. Sutker \& H. E. Adams (Eds.), Comprehensive handbook of psychopathology (3rd ed., pp. 259-276). New York: Plenum Press.

Kihlstrom, J. F., Tataryn, D. J., \& Hoyt, I. P. (1993). Dissociative disorders. In P. B. Sutker \& H. E. Adams (Eds.), Comprehensive handbook of psychopathology (pp. 203-234). New York: Plenum Press.
Korfine, L. \& Hooley, J. M. (2000). Directed forgetting of emotional stimuli in borderline personality disorder. Journal of Abnormal Psychology, 109, 214-221.

Lilienfeld, S. O., Lynn, S. J., Kirsch, I., Chaves, J. F., Sarbin, T. R., Ganaway, G. K., \& Powell, R. A. (1999). Dissociative identity disorder and the sociocognitive model: Recalling the lessons of the past. Psychological Bulletin, 125, 507-523.

Ludwig, A. M., Brandsma, J. M., Wilbur, C. B., Bendfeldt, F., \& Jameson, D. H. (1972). The objective study of a multiple personality. Archives of General Psychiatry, 26, 298-310.

MacLeod, C. M. (1989). Directed forgetting affects both direct and indirect tests of memory. Journal of Experimental Psychology: Learning, Memory, and Cognition, 15, 13-21.

McNally, R. J., Clancy, S. A., \& Schacter, D. L. (2001). Directed forgetting of trauma cues in adults reporting repressed or recovered memories of childhood sexual abuse. Journal of Abnormal Psychology, 110, 151156.

McNally, R. J., Metzger, L. J., Lasko, N. B., Clancy, S. A., \& Pitman, R. K. (1998). Directed forgetting of trauma cues in adult survivors of childhood sexual abuse with and without posttraumatic stress disorder. Journal of Abnormal Psychology, 107, 596-601.

Nissen, M. J., Ross, J. L., Willingham, D. B., MacKenzie, T. B., \& Schacter, D. L. (1988). Memory and awareness in a patient with multiple personality disorder. Brain and Cognition, 8, 117-134.

Peters, M., Uyterlinde, S. A., Consemulder, J., \& van der Hart, O. (1998). Apparent amnesia on experimental tests in dissociative identity disorder: An exploratory study. Conscious and Cognition, 7, 27-41.

Phaf, R. H., \& Wolters, G. (1991). Spontaneous completion frequencies for 168 two- and three- letter word stems (Tech. rep.). Leiden University. Leiden: The Netherlands:

Putnam, F. W., Guroff, J. J., Silberman, E. K., Barban, I., \& Post, R. M. (1986). The clinical phenomenology of multiple personality disorder: 100 recent cases. Journal of Clinical Psychiatry, 47, 285-293.

Silberman, E. K., Putnam, F. W., Weingartner, H., Braun, B. G., \& Post, R. M. (1985). Dissociative states in multiple personality disorder. Psychiatric Research, 15, 153-160.

Spanos, N. P. (1994). Multiple identity enactments and multiple personality disorder: A sociocognitive perspective. Psychological Bulletin, 116, 143-165.

Steinberg, M., Cicchetti, D., Buchanan, J., Hall, P., \& Rounsaville, B. (1993). Clinical assessment of dissociative symptoms and disorders: The Structured Clinical Interview for $D S M-I V$ dissociative disorders (SCIDD). Dissociation, 6, 3-15.

Terr, L. C. (1991). Childhood traumas: An outline and overview. American Journal of Psychiatry, 148, 10-20.

Ullsperger, M., Mecklinger A., \& Müller, U. (2000). An electrophysiological test of directed forgetting: The role of retrieval inhibition. Journal of Cognitive Neuroscience, 12, 924-940.

Vanderlinden, J., van Dyck, R., Vandereycken, W., Vertommen, H., \& Verkes, R. J. (1993). The Dissociation Questionnaire (Dis-Q): Development and characteristics of a new self-report questionnaire. Clinical Psychology and Psychotherapy, 1, 21-28.

Received July 30, 2001

Revision received August 16, 2002 Accepted August 19, 2002 